\title{
Different Animal Species Hairs as Biological Tool for the Forensic Assessment of Individual Identification Characteristics from Animals of Zoological Park, Pragti Maidan, New Delhi, India
}

\author{
Kapil Verma* and Bhawana Joshi
}

Amity Institute of Forensic Sciences (AIFS), B-Block, Lower ground floor, Amity University, Uttar Pradesh, Sec- 125, Noida-201303, Uttar Pradesh, India

\begin{abstract}
Ongoing research shows that how hair varies-between species and even on the same animals-and how he developed a database of mammal hair that can be used by wild life forensic scientist to identify hair in cases of illegal trafficking of the world's most endangered animals. Hair samples from some domestic and wild animals were evaluated in this study. The main hair structures (cuticle, cortex and medulla) were investigated. The guard hair diameter, colour, shaft, cuticle pattern, the medulla, the scale patterns and, root were examined using a light microscope.

The current research on morphologic characteristics of animal hair can be performed to provide more information for wild life forensics and allowing for the identification of illegal transport of animals, poaching or wildlife crime, fraud in textile and fur industry, and identification of their victims, etc.

In the present study, different animal hairs collected from National Zoological Park, Pragati Maidan, New Delhi, India were microscopically examined. Wild life animal species like Baby sheep hair, baby goat hair, bear hair, buffalo hair, cattle hair, deer hair, Doberman dog hair, dog hair, emu hair, flamingo feather, goat hair, Labrador dog hair, sheep hair, tiger hair identification /characterization using microscopic hair characteristics is discussed here. As part of a research project, this paper provides data that allow rapid and low cost animal species identification based on the hair microscopic features because hair is strongly resistant from decomposition and this property makes hair a nearly ideal type of physical evidence.
\end{abstract}

Keywords: Wild life forensic; Animal hair; Microscopy; Shaft; Cuticle pattern; Medulla pattern; Scale pattern; Fur; Zoo; Physical evidence

\section{Introduction}

Evidence of animal hair, is often discovered at crime scenes. Pet or other animal hairs can be found on the clothes of the victim or on other items of physical evidence collected at the crime scene. The identification and analysis of human and animal hairs from a crime scene can indicate physical contact between the victim and a suspect, or provide other investigative leads. Transferring of pet hairs to the victim, to a suspect, or to the crime scene may happen when the perpetrator is a pet owner (or when the victim owns a pet), or when the crime was committed in a place where animals are kept, such as barns, stables, basements, or transport vehicles [1].

Forensic hair analysis is a scientific method of analyzing trace evidence from a crime scene. It involves examining the hair shaft, including its medulla (inner core), cortex (intermediate layer) and cuticle (outer covering) through powerful microscopes. Hair evidence must be collected properly and analyzed according to protocols. The first step of the examination involves verifying whether the hair in question is that of a human or an animal. If the hair is from an animal, the examiner can potentially identify the species from which it originated [2].

Hair can be moved from location to location by physical contact, the presence of a specific person's hair can link a suspect or a victim to a crime scene. Transfer of hair is very common with animal hairs, which are commonly found on pet owners and in the environment of pet owners and can be used to link suspects to crime scenes. In hairs from animals, the diameter of the medulla is larger than half the diameter of the entire shaft. Animals produce different types of hair. They often have coarse guard hair external to softer fur hairs. They also produce whiskers and longer hairs in such places as the tail and mane [3].

\section{Methodology}

The hairs were collected from the baby sheep hair, baby goat hair, bear hair, buffalo hair, deer hair, Doberman dog hair, dog hair, emu hair, flamingo feather, goat hair, Labrador dog hair, sheep hair, tiger hair from animals of Zoological park, Pragati Maidan, New Delhi, India. Hairs were collected by using wide, transparent sticky tape lint roller. Hairs were cleaned and degreased in $70 \%$ ethanol and further investigated by light microscopy according to the quick method recommended in criminology. Hair samples were analyzed using a light microscope equipped with a video camera and connected to the image-analysis and morphometry system [4]. Microphotographs were taken with a digital camera at 20x or 40x magnification. Morphometric analysis of hair shaft, medullary diameter, cortex thickness and medullary vacuolated cells At least 10 measurements were performed in each hair sample. Cuticle scales were investigated by the rapid nail

${ }^{*}$ Corresponding author: Kapil Verma, Amity Institute of Forensic Sciences (AIFS), B-Block, Lower ground floor, Amity University, Uttar Pradesh, Sec-125, Noida-201303, Uttar Pradesh, India, E-mail: forensic.kapilalert@gmail.com

Received May 02, 2012; Accepted June 25, 2012; Published June 27, 2012

Citation: Verma K, Joshi B (2012) Different Animal Species Hairs as Biological Tool for the Forensic Assessment of Individual Identification Characteristics from Animals of Zoological Park, Pragti Maidan, New Delhi, India. J Forensic Res 3:160. doi:10.4172/2157-7145.1000160

Copyright: ( 2012 Verma K, et al. This is an open-access article distributed unde the terms of the Creative Commons Attribution License, which permits unrestricted use, distribution, and reproduction in any medium, provided the original author and source are credited. 
polish method hair shafts were embedded in a thin coat of clear nail polish applied on a glass microscope slide and when the polish surface was dried, the hair was removed leaving the scale covering on the slide [5]. The average distance between two consecutive scale margins (scale length, SL) and the scale pattern were also microscopically evaluated. Medulla pattern: Medullary index Human hair generally $<1 / 3$ Animal hair $>=1 / 2$ Medullary shape Human =normally cylindrical Animal $=$ varies by species

\section{Results and Discussions}

\section{Baby sheep hair}

The specific hair structure defined as wool fibers showed. Medulla is showed to be discontinuous, which is almost found near to the cuticle. Medulla cells develop large inter or intracellular space. Here we found scale pattern which are also criteria to detect out the differences between animals hairs according to the literature data. The scales were large rhomboidal asymmetric and protruding [6].

\section{Baby goat}

Hair is characterized by fine soft fibers. The goat is belongs to the subfamily Caprinae of the family Bovidae. The diameter is coarse [7]. Medulla is actually unbroken lattice, occupies nearly the entire width of the hair shaft. Absence of characteristic scale pattern, distinguishes goat from dear family and antelope hair. Scale pattern is imbricate. General aspect of the medullar lattice pattern was fan-shaped and mostly disposed transversely with respect to the longitudinal axis of the hair profile of the vacuolated cells was very sinuous with wavy margins. The curved margin was oriented towards the basis of the hair and the opposite angular margin toward the top of the hair. Large, unequal and anfractuous spaces were present around these particularly shaped medullar vacuolated cells very elongated transversely and arranged at an oblique angle with respect to the longitudinal axis of the hair. Scales were arranged in a herringbone pattern.

\section{Himalayan Bear (Black with a white chest)}

Dorsal guard hair was characterized by using light microscopy by studying features including color, hair thickness, cuticular characteristics, medulla pattern, medullary index etc. Medullar characteristics, we found a high medullary index and a vacuolated medulla. Medulla continuous, usually less than half overall shaft diameter, Unbanded: pigment coarse, granular and fairly even distribution. Scales imbricate [8].

\section{Jersey cow}

Diameter coarse Medulla absent or continuous, amorphous or vacuolated, width may be narrow to very broad (without mosaic pattern). Scales: imbricate and with no protrusions from hair shaft. Unbanded: ovoid structures abundant, pigment coarse. Root: elongated medullary structure continuous into root area, traces of follicular tissue may be present [9].

\section{Manipuri deer}

Deer hair is about $300-1000$ micron meter wide from the root to near the tip. It has a lattice type medulla that nearly fills the hair. the cuticle patterns is imbricating flattened to broadly acuminate and has a scale count about 3-7/100 micron depending upon the scale pattern. The characteristics diamond pattern is 3-4 scales/100 microns and the flattened to vermiform scales are around 7 [10]. Deer has a refractive index along its length of about 1.56 and perpendicular to its length of about 1.55. It has a birefringence of about 0.01 and a positive sign of elongation. Diameter: very coarse over all diameters (approximately $300 \mathrm{~m})$. Medulla; composed of spherical cells that occupy entire hair. Diameter constant throughout most of hair. Wine glass shape root. Regular, wave or crimp. Scale margins are round and isodiametric and resemble fish scales.

\section{Goat hair}

The angora breeds of goat produces long, lustrous lock of mohair on the surface. The Cashmere goat produces a commercial quality of cashmere wool, produced a medulla absent region (MAR) exists in the tip and root region of mammalian guard hair. Diameter: coarse. Medulla; unbroken lattice, occupies nearly entire width of hair shaft Scales; imbricate (absence of characteristics scales shapes or pattern distinguishes goat from deer and antelope hairs) [11].

\section{Buffalo hair}

Scientific name classified as "Bison bison", common name "Bison". Hair length increased posteriorly. The length/diameter ratio and diameter of non modulated hairs, of modulated hairs and of the medulla itself also varied between positions, as did the percentage of modulated hairs. The guard's hairs are hollow and range from 21-110 micron in diameter. The fines down hair are solid with a diameter of 12-29 micron and they have scales. Both types of hair vary less than 1 micron in diameter from root to tip. Through this specification, the buffalo hair will refer to the mixture of guard hair and down hair found in buffalo cape 20. Diameter: coarse, Medulla: continuous, amorphous or vacuolated, with may be narrow to very broad (without mosaic patterns) Scale: imbricate and with no protrusions from hair shaft. Unbanded; ovoid structures abundant, pigment coarse. Root; elongated, medullary structure continuous into root area, traces of follicular tissue may be present [12].

\section{Royal bengal tiger hair}

Diameter: fine, little variation. Medulla: Uniserial ladder (fur hairs), continuous, occasionally vacuolated in coarser hairs. Scales: They are not so prominent, may be banded. Root; elongated, no distinct shape, fibrils frayed at base of root. Black or melanistic colored tigers have been reported but further research is required before assessing whether these sighting were of true melanistic tigers or darker version of the orange tiger(with few large broad dark stripes) [13]. Tiger with white background coloration are not considered albinos. An albino would be pure white in color (no striping) and would have pink or red eyes, White tigers are leucocystic meaning that they have a recessive gene that causes them to lack dark colors [14].

\section{Sheep hair}

The wild ancestor's of today's domestic sheep had long, coarse hair and a short downy undercoat, which under domestication gradually became wool, while the long hair disappeared. Wild sheep such as mouflon, still do not have wooly coats.. Wools scaling and crimp make it easier to spin the fleece by helping the individual fibers attach to each other, so that they stay together. Because of the crimp, wool fibers have a greater bulk than others textiles and retain air, which causes the product to retain heat [15]. The amount of crimps corresponds to the fineness of the wool fibers. Here the medulla is found to be discontinuous, which is almost found near to the cuticle. Medulla cells develop large inter or intracellular space. Here we found scale patterns 
which are also criteria to detect out the differences between animal hairs [16].

\section{Hunting dog}

As in all other mammals, some hair follicles are in anagen, some in catagen, and some in telogen. Shedding, length of hair and presence or absence of an undercoat depends upon the timing of these cycles and the ratio of hair follicle in the various stages. Differences between summer coat and winter coat occurs because during the summer a greater numbers of follicles remains inactive [17]. Some breeds for e.g. poodles, tend to be low shedding because almost all of their follicles in anagen (growth cycle) almost all the time; their hairs continues to grow and has to be clipped. Some breeds of dog for e.g. Chinese crested have most of their follicles in telogen and thus may be almost completely hairless. Both breed are often listed as recommends for allergy sufferers. A dog's coat may be a double made up of a soft undercoat. Diameter; fine to coarse (usually coarser than cat hair): diameter may vary to give short hairs a barrel-like appearance. Medulla: Continuous, vacuolated to amorphous, occasionally very broad. Scales: generally not prominent. Unbanded; pigment occasionally very coarse and extending into roots $[18,19]$.

\section{Alsatian and doberman mixed breed hair}

This breed has a medium double length double coat which sheds constantly. The undercoat is typically a silvery grey and should not be visible through the outer coat. The hair is straight and lies close to the body. We'll sometimes find longer hair on the rear of the legs; the hair is thicker and longer around the neck. Adult guard will begin to grow up and out of this fluffy undercoat. Adults guard hairs are long single strand of hair that are harsh to the touch. These hairs will pop up through puppy's coat at the spine and appear at the tip of the tail and the scent gland area. Diameter; fine to coarse (usually coarser than cat hair); diameter may vary to give short hairs a barrel like appearance. Medulla: continuous, vacuolated to amorphous, occasionally very broad. Scales: generally not prominent [19].

\section{Labrador breed hair}

There are wide variations in colors and length of the hair specimen in the domestic animal group. The identifying characteristics given are general and apply in most cases. In order to distinguish between dog and cat and between beef (cattle) and horse, it is usually necessary that the root be present.

\section{Group characteristics}

Medium overall diameter (75-150) micron. Medulla: generally amorphous, moderate diameter variation in single hair. Hairs generally unbanded Characteristic root shape. Diameter; fine to coarse (usually coarser than cat hairs); diameter may vary to give short hairs a barrellike appearance. Medulla: continuous, vacuolated to amorphous, occasionally very broad. Scales: generally not prominent. Unbanded; pigments occasionally very coarse and extending into root [20].

\section{Feather of flamingo bird}

The feathers are made of a very light strong protein called keratin and two main pigment types in bird feathers are the red yellow carotenoids and the black, grey and brown melanin's. Melanin pigments are occurring in the form of granules. The lipochrome pigments tend to be diffused throughout the entire feather. James flamingos molt their wing and body feather according to their breeding schedule. There is no color differentiation between the males and females. We found hairy appendages at the sides of the feathers. Medulla can be absent or vacuolated. Scale pattern is observed and we find hairy long fiber extended from the sides of the feathers [21].

\section{Rosy pelican}

Two type's feathers: Clothing feathers and quill feathers. The central medulla is found with large number of empty cells. The outer edge is thickened. The outer edge displayed groups of small projections. No scale patterned.

\section{Emu}

They have two feathers to a single quill. Emu feathers are ruffled and bushy appearance which remind of hair more than feathers. They have brown to grey brown plumage of shaggy appearance, the shaft and the tips of the feather are black. Medulla is not continuous it can be present in fragmented form [22]. No hairy appendages are found. One side of the feather is very thick. No scale pattern is found. The central medulla is formed with the large number of vacuolated cells.

\section{Discussion}

Microscopic analysis of some animal's hair was performed and the preliminary data obtained in this study provide a useful tool for the forensic identification of the examined species. The investigation method employed in the present study is rapid and low cost. Specific identification can be performed on the hair, because its structure is generally very regular and all parts (cuticle, cortex and medulla) are easily detectable. The hair exhibits certain kind of microscopically characteristic, which can be associated with the source of known hair or may be with the similar breed. The hair can exhibit both similarities and slight differences and no conclusions can reach, Cuticular scales can be found of different forms and dimensions. We can use various characteristics to identify animal hair pigmentation, shaft diameter, scale pattern, medullary pattern and root shapes provide valuable information for specific identification of animal hair. Numerous scale patterns are found in animal hair, these patterns provide information for specific identification of animal hair. The size, shape and pattern arrangement on the hair provides distinctive characteristics for certain animals.

The distribution of the medulla is an important characteristic, this describes the presence of medulla along the hair shaft, absent, continuous or discontinuous or several terms used to describe the medulla distribution. Hairs are biological specimen and subjected to variations, in this we have to establish the variation in the sample. The possibility cannot be dismissed that there may be two hair samples whose range of variation overlap and distinguishing between the samples is not possible [23]. Based on our study, wild animals had a larger hair diameter than the domestic ones. No relevant differences were observed between the wild investigated species, Depending on the species, the scale shape and the outline of their margins show some particularities. In the wild animals the SL is always longer than that one found in the domestic species. This difference could be used as a useful feature in species differentiation.

Further studies are necessary to obtain hair data about other families of autochthonous animals in order to complete an adequate reference collection, essential for accurate animal species identification.

\section{References}

1. Boehme A, Brooks E, Mc naught I, Robertson J (2009) The persistence of 
Citation: Verma K, Joshi B (2012) Different Animal Species Hairs as Biological Tool for the Forensic Assessment of Individual Identification Characteristics from Animals of Zoological Park, Pragti Maidan, New Delhi, India. J Forensic Res 3:160. doi:10.4172/2157-7145.1000160

animal hairs in a forensic context. Australian Journal of Forensic Sciences 41: 99-112.

2. Bisbing RE (2001) Finding traces evidence. Trace evidence analysis. Houck, Max, (Edn) academic press, San Diego, California.

3. Bruner $\mathrm{H}$ (1974) The identification of mammalian hair. Hair atlases 176.

4. Crocker EJ (1998) A new technique for the rapid simultaneous examination of medullae and cuticular patterns of hairs. Microscope 46: 169-173.

5. Crocker JE (1999) Trace evidence in forensic evidence in Canada, (2 ${ }^{\text {nd }}$ Edn). Canadian law books Inc, aurora, ON.

6. Deed rick K (2004) Microscopy of hair. A practical guide and manual for animal hair 595-620.

7. Derrick DW, Sandra LK (2004) Microscopy of Hair Part II: A Practical Guide and manual for Animal Hairs.

8. Halverson JL, Basten C (2005) Forensic DNA identification of animal-derived trace evidence: tools for linking victims and suspects. Croat Med J 46: 598-605.

9. Bisbing RE, Wolner MF (1984) Microscopical discrimination of twins' head hair. J Forensic Sci 29: 780-786.

10. Pfeiffer I, Völkel I, Täubert H, Brenig B (2004) Forensic DNA-typing of dog hair: DNA-extraction and PCR amplification. Forensic sci int 141: 149-151.

11. Sato I, Nakaki S, Murata K, Takeshita H, Mukai T (2010) Forensic hair analysis to identify animal species on a case of pet animal abuse. International journal of legal mediciene 124: 249-256.

12. Partin KD (2003) A microscopically study of exotic animal hair. Modern microscopy journal.
13. Houck MM, Bisbing R, Watkins TG, Harmon RP (2004) The Science of Forensic Hair Comparisons and the Admissibility of Hair Comparison Evidence: Frye and Daubert Considered. Modern microscopy 7-10.

14. Stroud RK (1998) Wildlife forensic and the veterinary practitioner. J Exot Pet Medicine 7: 182-192.

15. Ogle RR, Mitosinka GT (1973) A rapid technique for preparing hair cuticular scale casts. J Forensic Sci 18: 82-83.

16. Paluzzi S, Mormino M, Vineis C, Tonin C, Patrone E, et al. (2004) anti keratin monoclonal antibodies for identifying animal hair fibers. Textile research journal 74: 458-464.

17. Kristen PD (2004) A microscopical study of exotic animal hairs: Part 2 Modern Microscopy Journal.

18. Robertson J (2009) Hair: microscopically analysis. Encyclopedia of forensic science 1415-1427.

19. Robert S Muller (2007) FBI law enforcement bulletin. 76: 310-383.

20. Robertson J (2009) Hair: microscopic analysis. Encyclopedia of forensic science 1415-1427.

21. Sahajpal V, Goyal SP, Thakar MK, Jayapal R (2009) Microscopic hair characteristic of few bovid species listed under wildlife protection act 1972 of india. Forensic sci int 189: 34-45.

22. Gupta SK (2010) Tiger Hair Analysis, by S.K. Gupta.

23. Kubic T, Petraco N (2003) Animal hair identification. Color Atlas and Manual of Microscopy for Criminalists, Chemists, and Conservators 69-76. 